\title{
From laboratory bench to benchmark: technology transfer in laboratory medicine
}

\author{
Federica Cariati $^{1 \#}$, Valeria D’Argenio ${ }^{1,2,3 \# \S}$, Raul Izquierdo ${ }^{4}$, Rossella Tomaiuolo $^{1,2,3}$ \\ ${ }^{1}$ KronosDNA Srl, Spinoff of Università Federico II, Napoli, Italy; ${ }^{2}$ Dipartimento di Medicina Molecolare e Biotecnologie Mediche, Università degli \\ Studi di Napoli Federico II, Napoli, Italy; ${ }^{3}$ CEINGE-Biotecnologie Avanzate Scarl, Napoli, Italy; ${ }^{4}$ Interlid Healthcare S1, Av. Monasterio Escorial \\ 10, Madrid, Spain \\ Contributions: (I) Conception and design: F Cariati, V D’Argenio, R Tomaiuolo; (II) Administrative support: None; (III) Provision of study materials \\ or patients: None; (IV) Collection and assembly of data: F Cariati, V D'Argenio, R Tomaiuolo; (V) Data analysis and interpretation: F Cariati, V \\ D’Argenio, R Tomaiuolo; (VI) Manuscript writing: All authors; (VII) Final approval of manuscript: All authors. \\ "These authors contributed equally to this work. \\ Correspondence to: Prof. Rossella Tomaiuolo, MD, PhD. Dipartimento di Medicina Molecolare e Biotecnologie Mediche, Università degli Studi di \\ Napoli Federico II, Via Sergio Pansini 5, 80131 Napoli, Italy. Email: rossella.tomaiuolo@unina.it.
}

\begin{abstract}
Background: Life Sciences research, enhancing the occurrence of innovation, is able to impact clinical decision-making, both at diagnosis and therapy. Indeed, starting from the knowledge of specific needs and of technical-scientific demands, researchers can conceive and experiment innovative solutions. Despite these strengths, transferring research to the market in Life Sciences shows considerable criticalities. The aim of this paper is to provide concrete evidences on the processes of technology transfer based on the exploitation of the results obtained by KronosDNAsrl, an academic spin-off focused on reproductive medicine.

Methods: Different tools were used to evaluate the technical feasibility (validation of the results obtained with the prototype) and to manage the technology transfer process of One4Two ${ }^{\circledR}$.

Results: The different analyses we carried out showed the feasibility of the proposed solution. As a result, the One4Two ${ }^{\circledR}$ prototype has been developed and validated.

Conclusions: Here, we provide a strength of evidences on how knowledge obtained by translational research on "bench" can be used to be transferred to the market on "benchmark" enabling innovation in Laboratory Medicine. In addition, the model described for One4Two ${ }^{\circledR}$ can be easily transferred to other products.
\end{abstract}

Keywords: Spin-off; laboratory medicine; technology transfer; fertility; health reproduction

Submitted Nov 12, 2019. Accepted for publication Jan 17, 2020.

doi: $10.21037 /$ atm.2020.02.61

View this article at: http://dx.doi.org/10.21037/atm.2020.02.61

\section{Introduction}

Life Sciences research has particular relevance since it has repercussions in the clinical practice (on both diagnosis and therapy) and, thus, on the occurrence of innovations. In this context, Laboratory Medicine operates at the frontiers of health care and research activities; this favours the knowledge of specific technical and scientific needs, facilitating translational research rather than in other areas (1). However, the development of innovative solutions transferable to the market is characterized by the need for important

${ }^{\S}$ Present affiliations: San Raffaele University Rome, via di Val Cannuta 247, 00166 Roma, Italy and CEINGE-Biotecnologie Avanzate scarl, Via Gaetano Salvatore 486, 80145 Napoli, Italy. 
investments (2), a very long "time to market" and specific economic-managerial skills. As a consequence, researchers are often unable to transfer their research results into products ready for the market (3). Nevertheless, the technology transfer process has become crucial for the universities that intend to give socio-economic, as well as cultural, value to the results of academic research. A vehicle for this type of entrepreneurial initiative are public research spin-offs, i.e., companies consisting mainly of university professors and researchers that base their activities on the know-how gained in the university. As reported in the Netval Report 2018 (http://netval.it/), 1,373 public research spin-offs are present in Italy, and this trend is rapidly growing. Interestingly, about $80 \%$ of the counted spin-offs have been established in the last 10 years, $90.4 \%$ of which originated from the universities, and the remaining $9.5 \%$ came from other public research institutes ( $6.3 \%$ operate in the biomedical sector).

This paper provides the concrete evidence on the exploitation of the results obtained by KronosDNAsrl (KronosDNA), a biomedical SME, spin-off of University of Naples Federico II, specialized in molecular diagnostics activities in the field of human reproduction. KronosDNA has been founded by three female researchers, involved in scientific and translational research, with the mission to combine scientific progresses and biotechnological innovations into genetic tests that meet the need to optimize the diagnostic path of infertile couples. In this context, the One4Two ${ }^{\circledR}$ project was born and developed.

The purpose of this paper is to show and to contextualize the activities that have allowed KronosDNA to transfer its research results to the market.

\section{The genetic tests in the diagnostic process of the infertile couple}

During the last decades, there were a series of stunning advancements in reproductive medicine and laboratory medicine that essentially led these two fields to be inextricably related; laboratory medicine now plays an essential role in all stages of the reproductive process, starting from diagnostic approaches up to the choice of the most complex therapy $(4,5)$.

To date, about 1 in 7 couples have trouble getting pregnant or sustaining a pregnancy (15\% of couples trying for a child) and 7.4 million women (11.9\%) have received fertility treatments in their lifetime (5). It has to be underlined that the conception requires the combined and precisely coordinated function of the reproductive system of both partners; as a consequence, the couple evaluation should be mandatory (5), while it is still unusual in the clinical practice (6). In this context, reproductive genetics has become even more important to support couples who are undergoing assisted reproductive technologies (ART) (Figure 1). However, genetic tests were considered ineffective (they identify only a few of the genetic variants related to infertility, compared to the advances reported in the literature) and inefficient (low detection rate, about $10 \%)(5-7)$. Moreover, during the genetic counselling activity, a high degree of patients' dissatisfaction emerged, which identified in the genetic test one of the major causes of "delay" in completing their entire diagnostic process (to date, infertile couples wait in average up to 9 months to have a diagnosis).

\section{One4Two: an integrated system designed to optimize the diagnostic process of the infertile couple}

Taking into account these needs, KronosDNA has developed One4Two ${ }^{\circledR}$, an integrated diagnostic system able to optimize the genetic diagnosis of infertile couples, looking for infertility cause and preventing further genetic alterations transmission. It is based on the next generation sequencing (NGS), a disruptive method able to simultaneously analyse millions of DNA fragments in parallel at very high speeds and specificities; however, it should be noted that bioinformatics skills are required for data interpretation specifications, which often represents the actual bottleneck of NGS-based procedures and the main limitation to their widespread distribution (8). In order to facilitate the routine use of One4Two ${ }^{\circledR}$, KronosDNA has designed a dedicated algorithm for the interpretation of data to solve current data management problems.

Ultimately, the combination of the innovative laboratory protocol and the diagnostic algorithm makes it possible to make genetic diagnosis more efficient (Figure 2).

\section{Methods}

In this session the methods used by KronosDNA to evaluate the feasibility of One4Two ${ }^{\circledR}$ are reported. The objective was not only to evaluate One4Two from a technological point of view, but even highlight the steps required to introduce it on the market. Ethics Approval was not required since market and technical analyses were carried out for this study. For the validation procedure (unpublished data) patients gave their informed consent to the use of their 


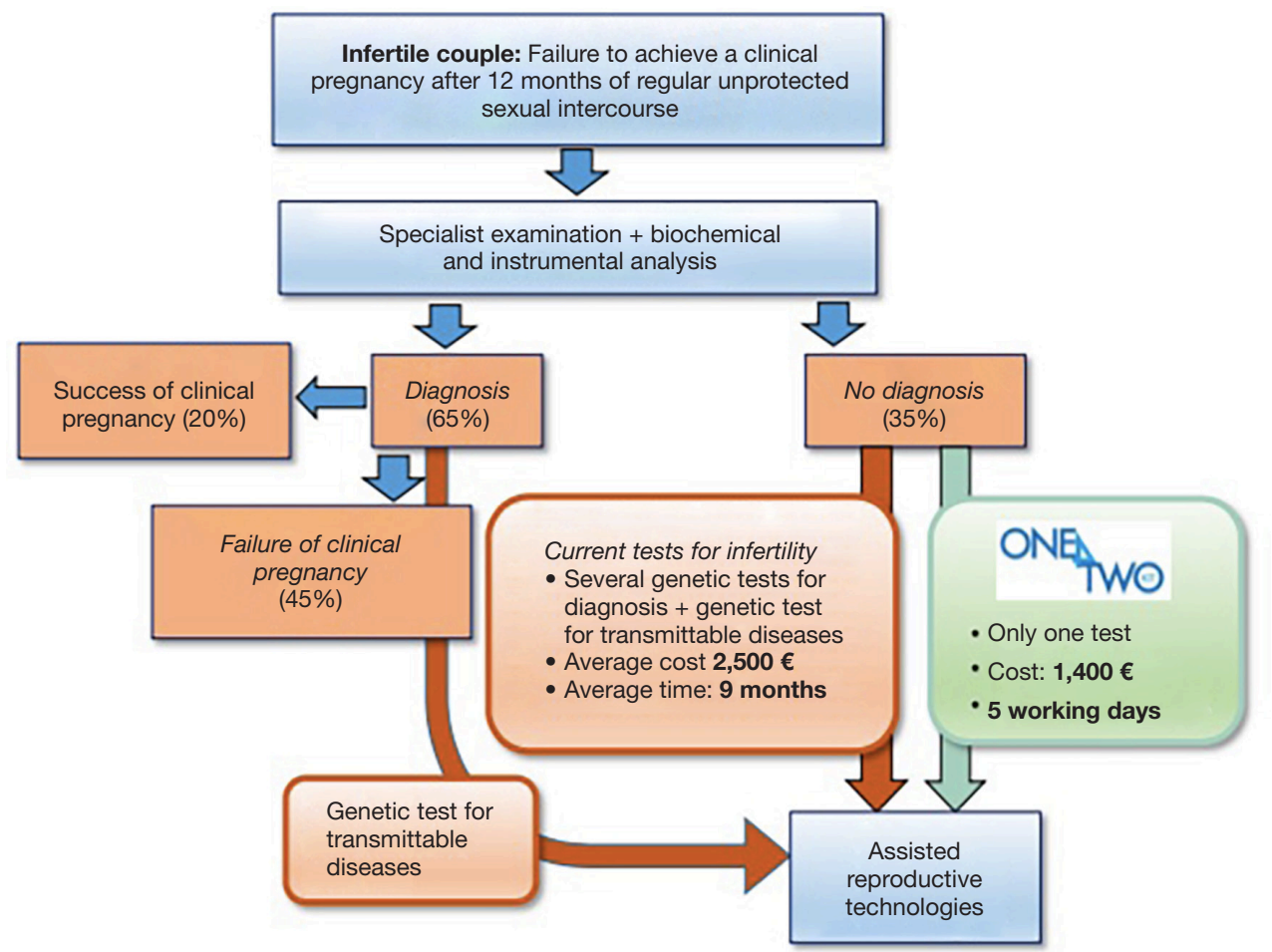

Figure 1 The current infertility diagnosis process is a long-lasting and exhausting process for the couple which, to determine the causes of infertility, has to carry out a series of specialist examinations, and biochemical and instrumental analyses. Nevertheless, a successful diagnosis is achieved only in about $65 \%$ of the cases. To the remaining undiagnosed $35 \%$, a series of genetic tests are prescribed, since several factors related to infertility have a genetic origin (i.e., chromosomal aberrations or single gene variants) and genetic diseases could have infertility as side-effect (i.e., phenotypes with multifactorial inheritance). Furthermore, all couples undergoing medically ART are required to carry out genetic tests to identify the most common genetic diseases that can be transmitted to their offspring. The traditional genetic diagnostic path (in orange in the figure) involves several series of tests with high costs and long diagnostic times (up to 9 months), as the couple must undergo several blood tests, often going to different laboratories, and the laboratories perform a dedicated analysis for each genetic disease, which requires different techniques and specialized laboratory personnel. Using One4Two ${ }^{\circledR}$ (in green in the figure) the couple must have only one blood sample withdrawal and all the results are obtained through a single laboratory protocol; the optimization of the entire diagnostic procedure is highlighted by the reduction of costs and times. ART, assisted reproductive technologies.

DNA in anonymous form.

\section{Methods used for technical feasibility assessing}

The technical feasibility study focused on the validation of the performances obtained with the prototype, starting from the laboratory procedures (sample preparation and integration with NGS) up to the analysis pipeline (processing time and reporting functionality). At this scope, KronosDNA used One4Two ${ }^{\circledR}$ to analyze in blind 70 DNA samples (48 for intralaboratory validation and 22 for interlaboratory validation) previously analysed with traditional lab methods (for instance Reverse Dot-Blot, Real-Time PCR, etc.) (unpublished data).
Furthermore, following a user-centred design approach, KronosDNA has also collected feedback from laboratory staff regarding the performance and characteristics of the laboratory procedures, in order to achieve the highest standards compliant with European guidelines for the management of genetic tests with NGS (9). For the same reason, feedbacks from gynaecologists were collected to test their satisfaction level.

\section{Methods used for technology transfer process management}

\section{The strategic planning}

Strategic planning, as a medium-long term forecasting method, has allowed to track the management of the 


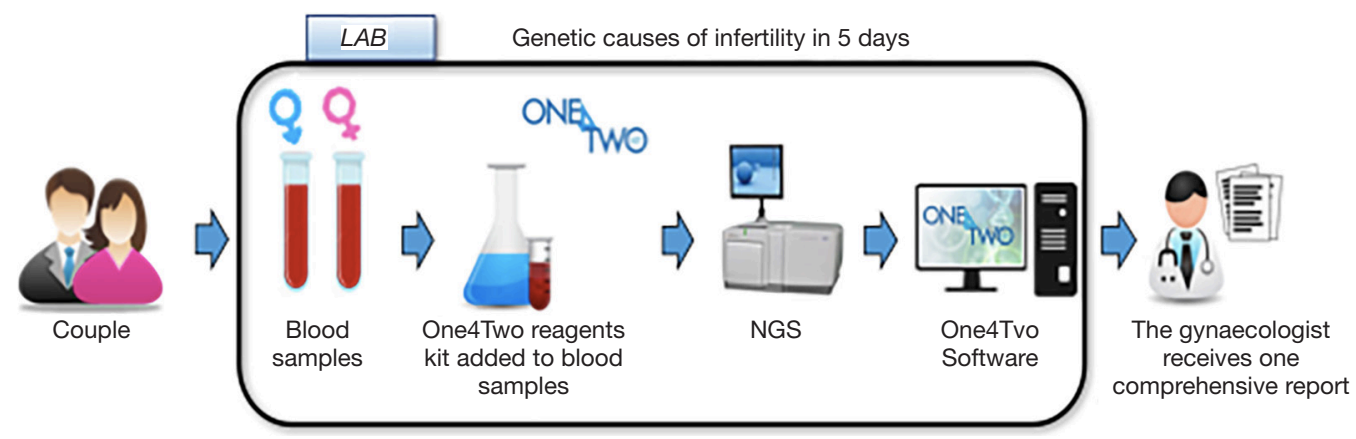

Figure 2 One4Two ${ }^{\circledR}$ flowchart. One4Two ${ }^{\circledR}$ requires a single blood sample for each member of the couple from which the DNA to be analyzed is extracted. Through a routine laboratory protocol, specific molecular probes react with the DNA of each patient to enrich a specific set of genes to be sequenced, thus highlighting the presence of possible alterations in the genes implicated in infertility and in those responsible for some of the most frequent hereditary genetic diseases. Data analysis is performed by a software, comparing the data of each patient with a reference control sample. All the information about the genes analyzed (carrier status for each individual, infertility causes and the risk of transmitting genetic pathologies to the offspring) are summarized in a single report for the couple by a dedicated algorithm. NGS, next generation sequencing.

Table 1 Evaluation of the state of the organization

\begin{tabular}{ll}
\hline Key elements & Declination \\
\hline Company mission & $\begin{array}{l}\text { Combine scientific processes and biotechnological innovations in genetic tests that meet the need to } \\
\text { optimize the diagnostic path of infertile couples } \\
\text { Strategic targets }\end{array}$ \\
$\begin{array}{l}\text { Development and commercialization of genetic tests for couple infertility that differ from those currently in } \\
\text { use in terms of efficiency (due to the innovative laboratory methods used), and of effectiveness (due to the } \\
\text { diagnostic algorithm designed for data management) } \\
\text { Informal and flat }\end{array}$ \\
$\begin{array}{l}\text { Financial resources } \\
\text { Human resources }\end{array}$ & $\begin{array}{l}\text { MD, PhD specialist in molecular diagnostics } \\
\text { MD, PhD specialist in gene sequencing }\end{array}$ \\
Biotechnologist, PhD specialist in human reproduction \\
Expertise
\end{tabular}

innovation focusing on strategic objectives and resource management, defining policies, and assessing risks/ opportunities. Starting from the assessment of the state of art (stage of development of the prototype, human and financial resources, skills present in KronosDNA, strengths and weaknesses), it was possible to identify the actions required and define the strategic objectives. The evaluation of the state of the organization (Table 1), the trend analysis (Table 2) and the stakeholder matrix (Figure 3) were carried out. The intersection of these data with the internal and external analysis provided the basis for the Strenghts,
Weaknesses, Opportunities and Threats (SWOT) analysis (Figure 4).

\section{The strategic control systems}

The application of strategic control systems leads to improve corporate performance, so it is important to implement its use also in spin-off companies such as KronosDNA. In this case, the Balanced Score Card (BSC) is a particularly useful tool in measuring performance (Figure 5), since it allows to align strategy, objectives and activities starting from the mission and from the vision. Through a 
Table 2 The trend analysis

\begin{tabular}{|c|c|c|c|}
\hline Trend & Notes & $\begin{array}{l}\text { Probability (from } \\
\text { 1-low to 5-high) }\end{array}$ & $\begin{array}{l}\text { Impact (from } \\
\text { 1-low to 5-high) }\end{array}$ \\
\hline Stable probability of infertility & 1 couple out of 5 ( 75 million) & 5 & 5 \\
\hline Almost $85 \%$ of infertile couples undergo genetic tests & - & 5 & 5 \\
\hline About 150 laboratories in Italy have NGS facility & NGS is diffusing fast in clinical practice & 5 & 5 \\
\hline Cost of genetic tests is decreasing & Thanks to the reduced cost of reagents & 5 & 1 \\
\hline Cultural changes towards proactive health system & $\begin{array}{l}\text { Patients are more informed (awareness } \\
\text { campaigns, independent) }\end{array}$ & 5 & 5 \\
\hline Creation of Consumer platforms & $\begin{array}{l}55 \% \text { of technological innovations in life } \\
\text { sciences }\end{array}$ & 5 & 5 \\
\hline $\begin{array}{l}92 \% \text { of physicians recognizes the utility of } \mathrm{Al} \text { and } \\
\text { cloud computing for data analysis }\end{array}$ & - & 5 & 5 \\
\hline
\end{tabular}

The trend analysis, based on the observation of the evolution of specific market trends related to infertility and genetic tests, has allowed to map the trends and to obtain strong insights that have been used to guide in the strategic choices. Al, artificial intelligence; NGS, next generation sequencing.

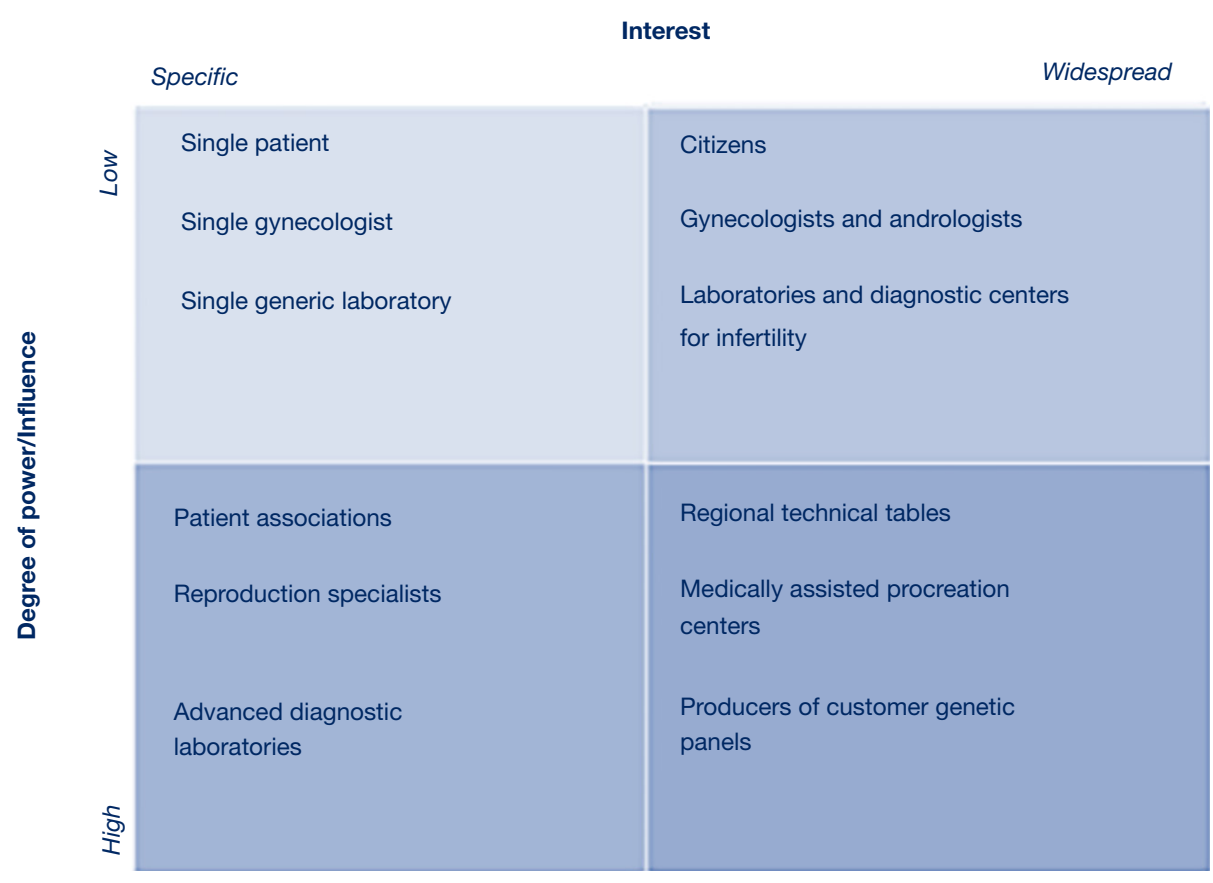

Figure 3 The stakeholder matrix. 


- Highly skilled team, with bioinformatics and medical competences
*-Pechnology and team highly recognized by the scientific community
-Price and analysis time is drastically better than competitors
-. Ability to attract private funds
Strenghts

- Growing demand for infertility screening

..Well defined customer and value chain

- Development of new tailored medical plan based on genetic data

- NGS diffusion is growing among fertility labs

Opportunities
- Low economic resources

- Low competences in marketing and management

-Distribution channels only partially active

-.Supply chain defined but still not contractualised

Weaknesses

- Diffusion of genetic panels specifically set for single pathology

..The culture of multi-pathology screening is still to be disseminated

-.Strong competition on fertility screening

..Single genetic tests price is lowering

Threats

Figure 4 The SWOT analysis. SWOT, Strenghts, Weaknesses, Opportunities and Threats.

\begin{tabular}{|c|c|c|c|c|}
\hline \multirow[t]{2}{*}{ MISSION } & \multicolumn{2}{|c|}{$\begin{array}{l}\text { To combine scientific progress and biotechnological innovations in genetic tests that } \\
\text { meet the need to optimize the diagnostic path of infertile couples }\end{array}$} & VISION & $\begin{array}{l}\text { To create a specific diagnostic tools } \\
\text { for reproductive medicine }\end{array}$ \\
\hline & STRATEGIC OBJECTIVES & KEY PERFORMANCE INDICATORS & TARGETS & INITIATIVES \\
\hline \multirow{3}{*}{$\begin{array}{l}\text { ¿ } \\
\bar{u} \\
z \\
\text { z } \\
\frac{1}{2}\end{array}$} & \multirow[b]{2}{*}{ finding financial resources } & grants received & $40 \%$ & participate in calls for $\pi$ activity \\
\hline & & financing from investment funds & $10 \%$ & contact investment funds \\
\hline & go to market & licencing out & $50 \%$ & marketing and comunication \\
\hline \multirow{3}{*}{ 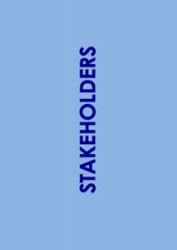 } & $\begin{array}{l}\text { patient and gynecologist } \\
\text { satisfaction }\end{array}$ & $\begin{array}{l}\text { reduction of time required for genetic testing } \\
\text { and increase in detection rate }\end{array}$ & $40 \%$ & \multirow[t]{2}{*}{$\begin{array}{c}\text { administer customer satisfaction } \\
\text { surveys }\end{array}$} \\
\hline & $\begin{array}{l}\text { satisfaction of the laboratories } \\
\text { that use One4Two }\end{array}$ & $\begin{array}{l}\text { optimization of the analytical path and cost } \\
\text { reduction }\end{array}$ & $40 \%$ & \\
\hline & $\begin{array}{l}\text { satisfaction of the Academic } \\
\text { environment }\end{array}$ & publication of scientific papers & $10 \%$ & $\begin{array}{l}\text { organize data and write scientific } \\
\text { works }\end{array}$ \\
\hline \multirow{3}{*}{ 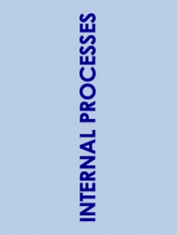 } & $\begin{array}{l}\text { optimization of the analytical and } \\
\text { diagnostic process }\end{array}$ & $\begin{array}{l}\text { reduction of time required for genetic testing } \\
\text { and increase in detection rate }\end{array}$ & $30 \%$ & set up and validation of One4Two \\
\hline & increase in detection rate & reduction in the rate of idiopathic infertility & $30 \%$ & database machine learning \\
\hline & $\begin{array}{l}\text { compacting of the diagnostic } \\
\text { path }\end{array}$ & reduction of time to pregnancy & $40 \%$ & operation management \\
\hline \multirow{2}{*}{ 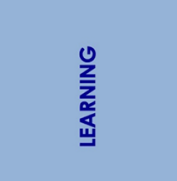 } & $\begin{array}{l}\text { continuous updates on the } \\
\text { relevant scientific literature }\end{array}$ & implementation of the gene panel & $50 \%$ & $\begin{array}{c}\text { consult the scientific literature, } \\
\text { participate in courses and } \\
\text { congresses }\end{array}$ \\
\hline & $\begin{array}{l}\text { to maintain the analytical and } \\
\text { diagnostic quality of One4Two }\end{array}$ & quality control & $50 \%$ & $\begin{array}{l}\text { participate in quality control } \\
\text { programs organized by national } \\
\text { and European networks }\end{array}$ \\
\hline
\end{tabular}

Figure 5 The Balanced Score Card (BSC).

top-down process, with the aim of organizing the multiple activities of all of the company, it provides the complete picture of operating activities, facilitating communication and understanding in relation to the defined objectives.

\section{Market analysis and business assessment}

To validate the business model and the price strategy, the current market for infertility tests was investigated by surveying the intended customers (genetic analysis labs). A 
- Possible raise of COGS could affect pricing strategy

- Taxes could raise

- Cost of personnel could raise

- Scale-up of production volumes could lower final price
- Possible raise of new competitor technologies

- R\&D expenses could raise too much

- Reliability could be below existing methods
- Certifications required to go to market is currently changing in Europe and could change in other countries

- Freedom to operate could be limited to certain countries

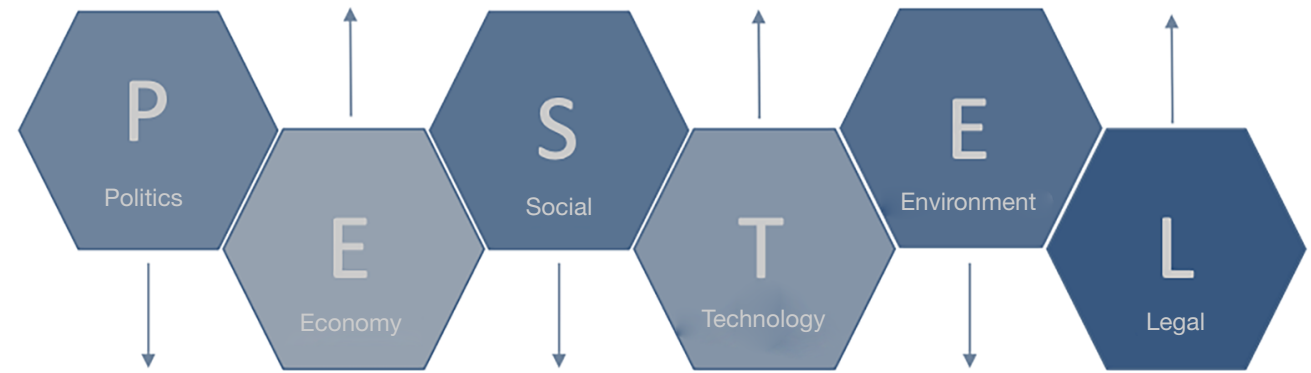

- Legislation concerning fertility test could change

- Some countries could limit the use of genetic tests due to data management concerns

- Legislation concerning patents could change

Figure 6 The PESTEL analysis. COGS, cost of goods sold; PESTEL, Political, Economic, Socio-cultural, Technological, Environmental and Legal.

cost-benefit analysis, including the definition of the business case, was also included to assess the economic benefits for both laboratories and the infertile couples.

To better define the product ecosystem in-depth market analysis was also assessed, including the current and prospect competitors, as well as a Political, Economic, Socio-cultural, Technological, Environmental and Legal (PESTEL) analysis (Figure 6). In particular, the different national health systems, regulations linked to genetic tests, economic subsidies, public/private nature of the laboratories were taken into account.

\section{Results}

\section{Results obtained from the assessment of technical feasibility}

The results obtained by One4Two ${ }^{\circledR}$ from the validation of both the laboratory procedures and data interpretation are perfectly comparable with those obtained with traditional methods, without false positives nor false negatives, thus reaching TRL 9 (Technology Readiness Level) and providing $100 \%$ accuracy.

From the analysis of the utility and satisfaction questionnaires, we obtained the feedbacks of the consulted focus groups. In particular, the laboratories gave very positive feedback on the efficiency of the workflow, and the gynaecologists showed satisfaction for the diagnostic effectiveness.

\section{Results obtained from the evaluation of the management of the technology transfer process}

The analysis of the state of the art has shown that KronosDNA's mission and objectives were well defined, as well as the technical-scientific skills to develop and validate One4Two; financial resources to purchase laboratory reagents and to integrate the skills were instead necessary.

Trend analysis has allowed us to investigate both the trends related to infertility and those related to genetic tests. It turned out that infertility permanently involves a high number of couples, who undergo specialized care (the number of specialists in the field of reproduction is limited) and specific genetic tests. At the moment there are no genetic panels for infertility in NGS, but that the use of this technology has a rapid diffusion as it has a positive impact on the entire diagnostic process.

Stakeholder analysis was useful for identifying: (I) reproduction specialists as the subjects to be involved in evaluating the completeness of the genetic panel; (II) biotechnology companies with technological affinity, but 


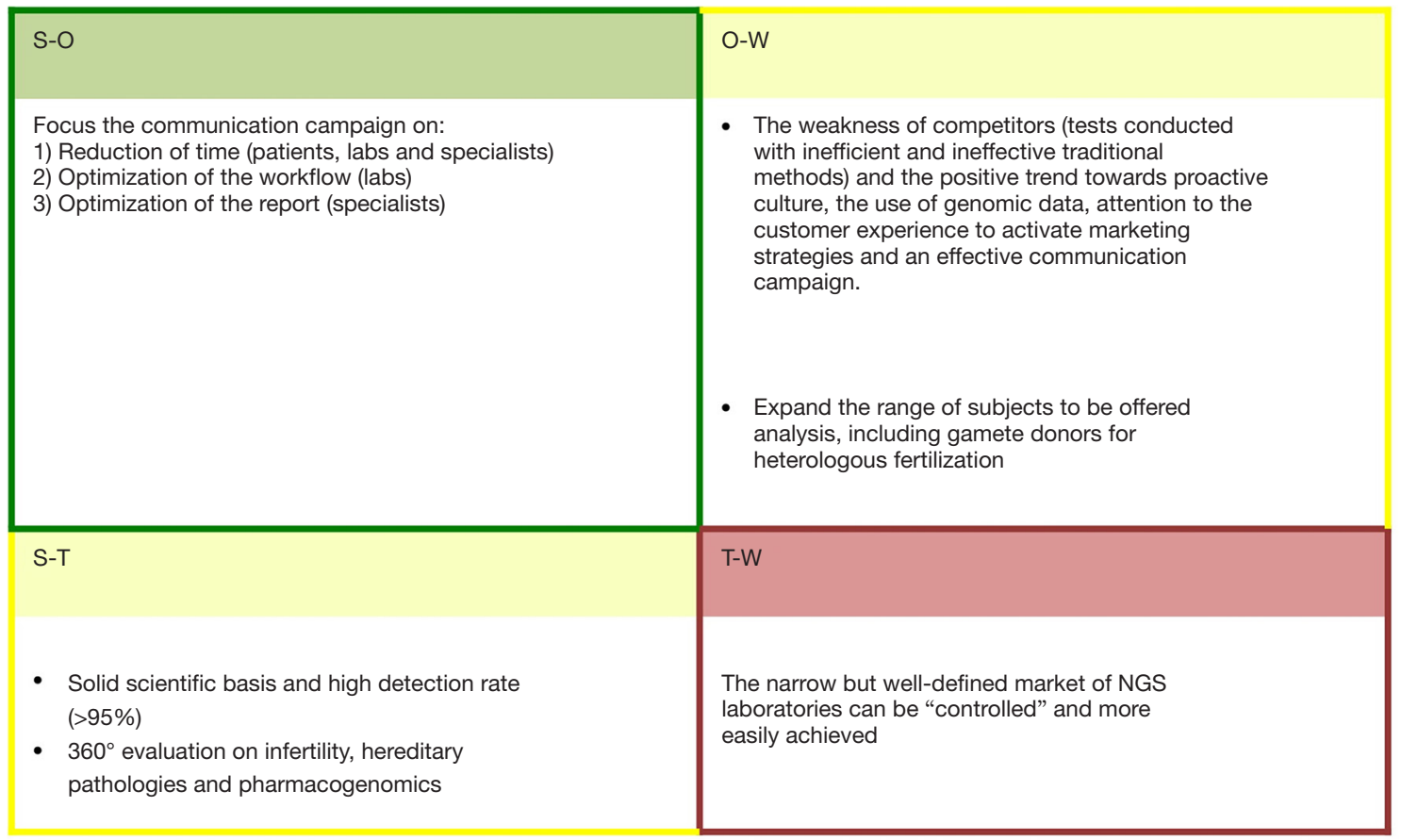

Figure 7 The results of the SWOT analysis. SWOT, Strengths, Weaknesses, Opportunities and Threats.

different diagnostic purposes for collecting contextual information; and (III), finally, laboratories and patients in the external review of effectiveness and efficiency.

Taking into consideration the SWOT analysis, it was possible to identify the factors that can create (green) and destroy (red) the company value, and all the factors to be kept under control (yellow) (Figure 7).

The strategic control systems implemented by KronosDNA have been defined according to the control levers devised by Robert Simons (10). The values of KronosDNA were formalized in the Mission ("Combining scientific progress and biotechnological innovations in genetic tests that respond to the need to optimize the diagnostic path of infertile couples") and in the corporate Creed ("Dealing with motherhood is a qualifying way of thinking about a model of growth and development"). Mission and corporate Creed are reported in the introductory/presentation section of the business plan, in the summary documents presented to the stakeholders or to potential investors. The positivity expressed has supported the definition of the strategy and has motivated the team, towards a participatory approach by decisively resolving the external environmental difficulties.

The Vision ("To create specific diagnostic tools for reproductive medicine") clearly states that the strategic positioning of the company is a biotech company engaged in the R\&D of diagnostic genetic tests in the field of reproductive medicine, but not in screening or predisposition genetic tests. This has defined the presence of limits to the strategic opportunities that can be pursued (indeed, from the analysis of the trends there is a growing presence on the market of multi-gene tests for screening or predisposition), avoiding pursuing objectives that are not consistent with the company's mission and with the code of professional ethics, to which the team refers (limits to behaviour).

The Diagnostic Control system was based on the feedback mechanism, considering as output One4Two ${ }^{\circledR}$ s validation and introduction on the market, and as additional performance indicators the ability to attract grants for technology transfer activity, and to produce scientific publications. This allowed to support the team in future strategic decisions (allocation of resources in marketing and communication), encouraging and motivating towards the scale-up phase.

Finally, the coaching program, which KronosDNA benefited as winner of Horizon2020 PMI instrument, was identified for the interactive control system. This program focused on identifying strategic key factors for the internationalization (analysis of European legislation and regulations beyond Italian regulation) and on the inclusion 
of new strategic choices (implementation of clinical competence to optimize patients' governance).

Moreover, during this stage the current market for infertility test was investigated; it is forecasted to have positive trend, due to the declining fertility rates across the globe, the increasing of the age for the first-time pregnancy and the introduction of user-friendly fertility monitors which facilitate the whole pregnancy path for the couple (11-13). The analysis of the competitors was also carried out, and it turned out that the main competitors of KronosDNA are to be considered companies that already produce diagnostic kits for NGS. Their advantages are the consolidated distribution and high expertise in the sector, but they lack specific know-how on infertility tests and interpretation of data for diagnostic purposes, as proved by the fact that often they don't produce bioinformatics pipeline software for genetic analysis. The global market is dominated by a few top producers (i.e., Illumina, Thermo Fisher Scientific, and Pacific Biosciences) which produce both NGS instruments and kits for different genetic test.

The Cost Benefit Analysis quantified the economic benefits and costs for both laboratories and the infertile couples: One4Two ${ }^{\circledR}$ allows to complete the entire diagnostic process in 1-2 months (of which only 5 days for the genetic test at the cost of $€ 1,400$ per couple) and to reduce the time to pregnancy (from 9 to $1-2$ months). The detection of average prices applied on the market for similar diagnostic kit types has established that for the entire diagnostic journey today the couple spends at least $€ 2,500$ ( $€ 1,250$ per patient); using One4Two ${ }^{\circledR}$, the final price for the couple will be $€ 1,400$ ( $€ 700$ per patient).

\section{Discussion}

Since its foundation (June 2016), KronosDNA has mainly carried out research and development activities aimed at the development and the commercialization of genetic tests that differed in terms of efficiency (due to innovative laboratory methods) and effectiveness (due to a diagnostic pipeline). One4Two ${ }^{\circledR}$ is radically changing the current diagnostic approach from the direct search for known infertilityrelated genetic mutations (each requiring a dedicated test) to a comprehensive DNA scanning able to highlight all the mutations; it allows to reduce the analytical times and costs, has a positive impact on the entire diagnostic process.

One4Two ${ }^{\circledR}$ is poised to provide the following unique benefits to the end-users and indirect beneficiaries of its adoption:
* Genetic laboratories (customers) will add to their test portfolio an innovative system, which will make them save costs (drastically reducing the workload for interpreting data) and increase their customer base.

* Infertile couples (end users and main beneficiaries) will have the complete genetic characterization in 5 days and at an estimated cost of $€ 1,400$ per couple (based on our preliminary interviews with labs and gynaecologists).

* Gynaecologists (main drivers) will receive a unique and complete diagnostic report, easy to interpret to define the diagnosis, the most suitable therapy, and the indication for the antenatal diagnosis.

KronosDNA was born with an informal and flat organizational structure, focused on the production of a single innovative product placed in a defined market segment. The founders dealt directly with the most important strategic choices including among others capital management. The strategy was not the result of an explicit design, but the sum of actions that followed one after another according to a logical thread inspired by the corporate aims. KronosDNA used programming and control tools oriented to multidimensional measurement in the short term. In particular, they are based on a system with low centrality, fed both by monetary indicators (e.g., income statement, price-balance of reagents) and nonmonetary indicators (e.g., intra and extra-lab validations) that suit dynamic systems that are being defined and developed.

KronosDNA's activities were carried out thanks to the grant destined to the technological transfer that KronosDNA was able to attract and its own capital. One4Two ${ }^{\circledR}$ was introduced on a benchmark market in February 2019.

The role of the ecosystem of innovation and the initiatives that the universities have adopted to support entrepreneurship, by increasing the propensity to create business (14-17), have been essential in the first phase of development of One4Two ${ }^{\circledR}$.

The grants and training courses received allowed the development of the prototype and the planning of a strategy aimed at realizing the project in an academic context and bringing innovation to clinical practice. The milestones of KronosDNA has been reconstructed in Figure 8.

Among the key elements for the birth and development of KronosDNA there is certainly the team: the union of their knowledge, skills and experience has allowed to obtain the results of the research that led to the development of 


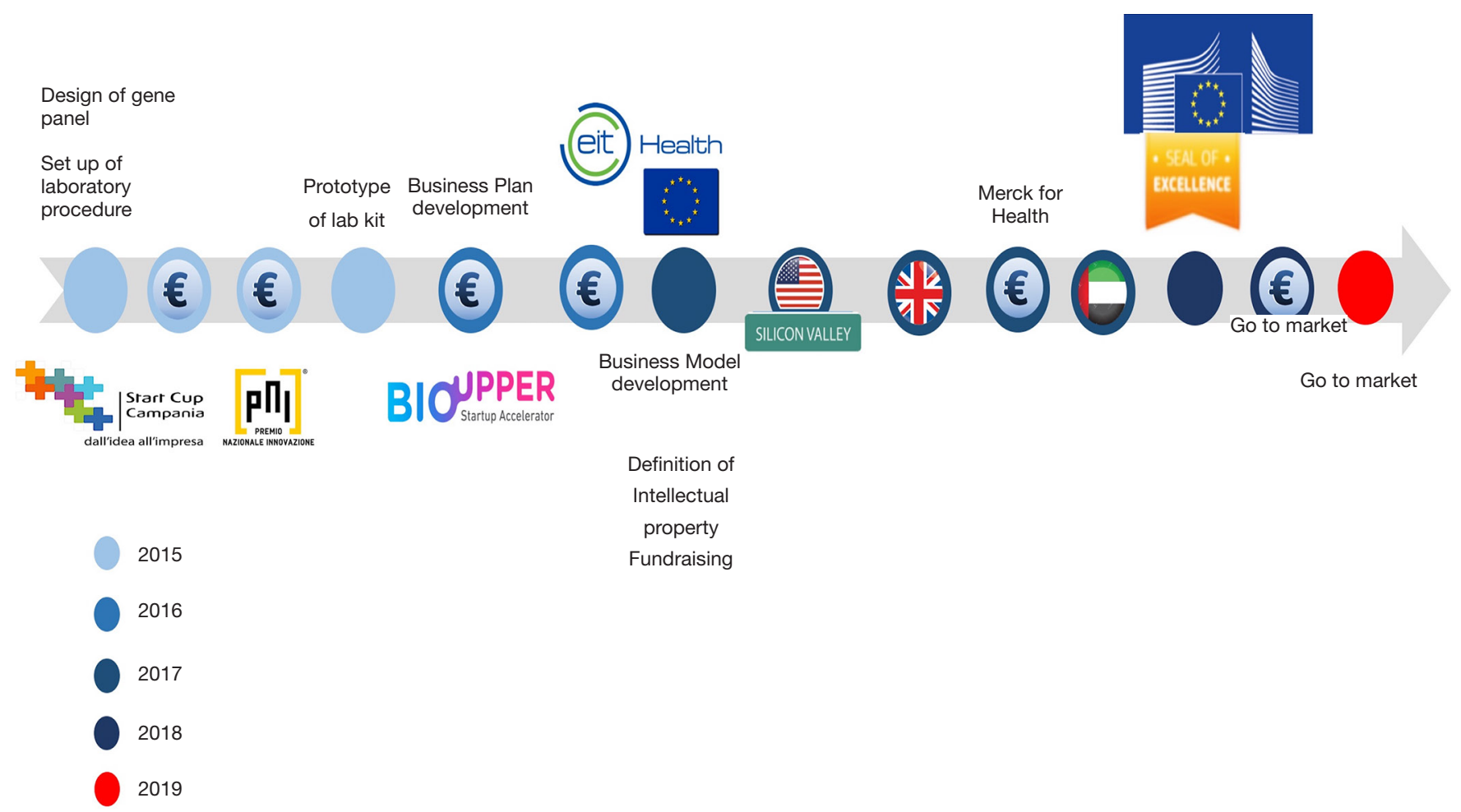

Figure 8 Milestones of KronosDNA from the generation of the idea until today. One4Two ${ }^{\circledR}$ was still in an embryonic state when it won one of the regional StartCup awards in 2015 and later the Special Mention on "female entrepreneurship" at the National Innovation Award (http:// www.pnicube.it/). The idea was consolidated thanks to the participation in BioUpper, a training course at PoliHub (https://www.polihub. it), the incubator of the Politecnico di Milano, and EIT-Health Innostars program (https://www.eithealth.eu/innostars) during which the team started planning a strategy and understood the importance of setting up a spin-off to be able to carry out the project and place the innovation in the clinical practise.

One4Two ${ }^{\circledR}$. Unlike the undisputed statistical evidence of a lower quantitative presence of female business owners $(18,19)$, never exceeding $18 \%$ of the startup population (20), KronosDNA was founded and managed by an exclusively female team. Moreover, some studies report that the innovative female-driven startups, founded in recent years, have underperformed those of men (21). However, this has not been confirmed for those, based on innovative scientific or technological initiatives (22); where competence and knowledge are factors on which to build the corporate value proposition and the gender variable has no impact on business performance (23). In agreement with what emerged from the exploratory survey by Demartini and Marchegiani (24), the critical success factors for KronosDNA, in addition to knowledge and skills, are participatory leadership that promoted integrated thinking and participatory processes of co-creation.

However, it is certainly clear that the availability of financial resources plays a central role in the competitive growth of a spin-off (25). In the initial phases, the financing with own capital and the grants obtained from the participation in national and international competitions for start-ups allowed to advance the research up to the validation of One4Two ${ }^{\circledR}$. Thanks to the latest grant received by the European Commission under the H2020SME Instrument program, it will be possible to establish marketing and communication activities for the launch of One4Two ${ }^{\circledR}$ on a broader market. Having the requisites to participate and obtain a European grant was important, above all as an internationalization opportunity in order to build a network and an international reputation.

In this path, it is clear that the phases that go from the moment of invention to that of first prototyping are those that require financing (26). Some universities have started experimental initiatives in this field using their own funds, but this approach seems not to be sustainable at the system 
level. The experience of many universities belonging to European countries has demonstrated the need and effectiveness of these initiatives (27). It is, therefore, hoped that funding will be made available given the crucial role played by universities as a forge for the development of new spin-offs.

\section{Conclusions}

Promoting the "third mission" means promoting the enhancement and use of knowledge in order to contribute to the development of the society through the development of new business realities. To achieve this goal, it is necessary to involve teaching staff, researchers, $\mathrm{PhD}$ students and also students $(28,29)$, and to strengthen the Technology Transfer Offices. In recent years, some universities have adopted measures to support entrepreneurship by increasing the propensity to create business, promoting the creation of ad hoc support contexts for business start-ups $(15,16)$. Currently, it has been already planned, and in some universities is already taking place, to implement doctoral courses with teachings on the theme of the technology transfer. Starting from its own experience, the KronosDNA team believes that it is a very important activity and suggests its extension also for undergraduate courses, starting from those of the STEM sectors. The coordination of these courses with the Technology Transfer Offices of the university would be desirable.

Much of empirical research in university entrepreneurship is devoted to the emergence of research spin-offs $(30,31)$, while it is not so explored the mode, not only financial, for their accompaniment to consolidation. In the case of KronosDNA, in which the team is characterized by mainly scientific know-how, the Technology Transfer Office has played an important role above all in the early stages of setting up the spin-off and management of intellectual property (32). We reiterate the need to support activities to support company consolidation through legal, economic, mentoring, etc. (33). Strengthening the Technology Transfer Offices of Universities and Research Institutions means, looking at international experience, endowing them with profiles featured by high professionalism, multidisciplinary, and multi-sectorial skills in order to facilitate contacts between the academic world and entrepreneurship, and consolidate the entrepreneurial activity born on the basis of public research. Beyond the direct economic and employment impact, these are highly knowledge-based companies that, with their inclusion in the productive chains of the respective territories, may contribute to fueling their competitiveness and dynamism.

\section{Acknowledgments}

Funding: This study was supported by a grant from the European Commission within the Horizon 2020 activities (EIC-SME Instrument 2018-2020 area, N. 855720); and by EIT Health InnoStars Awards Competition, year 2016.

\section{Footnote}

Conflicts of Interest: The authors have no conflicts of interest to declare.

Ethical Statement: The authors are accountable for all aspects of the work in ensuring that questions related to the accuracy or integrity of any part of the work are appropriately investigated and resolved. For the validation procedure (unpublished data) patients gave their informed consent to the use of their DNA in anonymous form.

Open Access Statement: This is an Open Access article distributed in accordance with the Creative Commons Attribution-NonCommercial-NoDerivs 4.0 International License (CC BY-NC-ND 4.0), which permits the noncommercial replication and distribution of the article with the strict proviso that no changes or edits are made and the original work is properly cited (including links to both the formal publication through the relevant DOI and the license). See: https://creativecommons.org/licenses/by-nc-nd/4.0/.

\section{References}

1. Bozeman B, Rimes H, Youtie J. The Evolving State-ofthe-Art in Technology Transfer Research: Revisiting the Contingent Effectiveness Model. Research Policy 2015;44:34-49.

2. Clarysse B, Tartari V, Salter A. The impact of entrepreneurial capacity, experience and organizational support on academic entrepreneurship. Research Policy 2011;40:1084-93.

3. Swamidass PM, Vulasa V. Why university inventions rarely produce income? Bottlenecks in university technology transfer. J Technol Transf 2009;34:343-63.

4. Cariati F, Savarese M, D'Argenio V, et al. The SEeMORE strategy: single-tube electrophoresis analysis-based genotyping to detect monogenic diseases rapidly and 
effectively from conception until birth. Clin Chem Lab Med 2017;56:40-50.

5. Cariati F, D'Argenio V, Tomaiuolo R. The evolving role of genetic tests in reproductive medicine. J Transl Med 2019;17:267.

6. Hussein N, Weng SF, Kai J, et al. Preconception risk assessment for thalassaemia, sickle cell disease, cystic fibrosis and Tay-Sachs disease. Cochrane Database Syst Rev 2015;(8):CD010849.

7. Harper JC, Aittomäki K, Borry P, et al. Recent developments in genetics and medically assisted reproduction: from research to clinical applications. Eur J Hum Genet 2018;26:12-33.

8. D'Argenio V. The High-Throughput Analyses Era: Are We Ready for the Data Struggle? High Throughput 2018. doi: 10.3390/ht7010008.

9. Matthijs G, Souche E, Alders M, et al. Guidelines for diagnostic next-generation sequencing. Eur J Hum Genet 2016;24:2-5.

10. Simons R. Levers of control: How managers use innovative control systems to drive strategic renewal. Harvard Business Press, 1994.

11. Warner L, Jamieson DJ, Barfield WD. CDC releases a National Public Health Action Plan for the Detection, Prevention, and Management of Infertility. J Womens Health (Larchmt) 2015;24:548-9.

12. Quinn MM, Cedars MI. Declining Fertility with Reproductive Aging: How to Protect Your Patient's Fertility by Knowing the Milestones. Obstet Gynecol Clin North Am 2018;45:575-83.

13. Thirumavalavan N, Gabrielsen JS, Lamb DJ. Where are we going with gene screening for male infertility? Fertil Steril 2019;111:842-50.

14. Shane S. Academic entrepreneurship: University spinoffs and wealth creation. Cheltenham: Edward Elgar Publishing, 2004.

15. Boardman C, Bozeman B. Role strain in university research centers. J Higher Educ 2007;78:430-63.

16. Ambos TC, Mäkelä K, Birkinshaw J, et al. When Does University Research Get Commercialized? Creating Ambidexterity in Research Institutions. Journal of Management Studies 2008;45:1424-47.

17. Siegel DS, Wright M. University technology transfer offices, licensing, and start-ups, in the Chicago handbook of university technology transfer and academic entrepreneurship. Chicago, IL: University of Chicago Press, 2015.

18. Micozzi A, Micozzi F, Pattitoni P. Fostering Female
Entrepreneurship in Academic Spin-offs. In: Audretsch DB, Lehmann E, Meoli M, et al. editors. University Evolution, Entrepreneurial Activity and Regional Competitiveness. Switzerland: Springer International Publishing, 2015;49-68.

19. Berger ESC, Kuckertz A. Female entrepreneurship in startup ecosystems worldwide. J Bus Res 2016;69:5163-8.

20. Startup Genome. Global Startup Ecosystem Report 2018. Available online: https://startupgenome.com/ reports/2018/GSER-2018-v1.1.pdf

21. Fairlie RW, Alicia MR. Gender differences in business performance: Evidence from the Characteristics of Business Owners survey. Small Business Economics 2009;33:375.

22. Kuschel K, Lepeley MT. Women start-ups in technology: Literature review and research agenda to improve participation. International Journal of Entrepreneurship and Small Business 2016;27:333-46.

23. Demartini P. Innovative Female-Led Startups. Do Women in Business Underperform? Adm Sci 2018;8:70.

24. Demartini P, Marchegiani L. Born to Be Alive? Female Entrepreneurship and Innovative Start-Ups. In IPAZIA Workshop on Gender Issues. Cham: Springer 2018;219-35.

25. Visintin F, Pittino D. Founding Team Composition and Early Performance of University-Based Spin-off Companies. Technovation 2014;34:31-43.

26. Rasmussen E, Sørheim R. Obtaining early-stage financing for technology entrepreneurship: reassessing the demandside perspective. Venture Capital 2012;14:77-89.

27. Landry R, Amara N, Cloutier JS, et al. Technology transfer organizations: services and business models. Technovation 2013;33:431-49.

28. Colombo MG, Piva E. Firms' genetic characteristics and competence enlarging strategies: A comparison between academic and non-academic high-tech start-ups. Research Policy 2012;41:79-92.

29. Saridakis G, Lai Y, Cooper CL. Exploring the relationship between HRM and firm performance: A meta- analysis of longitudinal studies. Human Resource Management Review 2017;27:87-96.

30. Powers JB, McDougall PP. University start-up formation and technology licensing with firms that go public: a resource-based view of academic entrepreneurship. J Bus Ventur 2005;20:291-311.

31. Ramaciotti L, Rizzo U. The Determinants of Academic Spin-off Creation by Italian Universities. R\&D Management 2015;45:501-14. 
32. Owen-Smith J, Powell WW. To patent or not: faculty decisions and institutional success at technology transfer. J Technol Transf 2001;26:99-114.

Cite this article as: Cariati F, D'Argenio V, Izquierdo R, Tomaiuolo R. From laboratory bench to benchmark: technology transfer in laboratory medicine. Ann Transl Med 2020;8(6):353. doi: 10.21037/atm.2020.02.61
33. Abrams I, Leung G, Stevens AJ. How are US technology transfer offices tasked and motivated. Is it all about the money? Research Management Review 2009;17:1-34. 